\title{
A New Thermal Integrity Method for Pile Anomaly Detection
}

\author{
QIANCHEN SUN and MOHAMMED Z.E.B. ELSHAFIE*
}

\begin{abstract}
Anomaly detection is a hot topic in pile construction which is a complex one due to the intrinsic nature of underground structures, such as limited accessibility, large depth and complex soil profile. Several traditional pile integrity tests have been developed before, which, however, cannot give detailed information of anomaly size, nature or precise location. This paper proposes a new thermal integrity testing method that employs distributed temperature sensors and combines concrete heat hydration numerical model. The fundamental principle is that early-age concrete releases heat during curing. If defects such as voids, necking, bulging and/or soil intrusion exist inside the concrete body, they will result in local temperature variations. The developed numerical model uses Finite Element Method (FEM) to simulate concrete hydration and heat transfer. The model can be customised for different concrete mixes, pile geometries and built-in anomalies. The modelling results are then compared to field test temperature data. Any temperature disparities indicate potential anomalies of the pile structure. The proposed new test will reduce the cost and increase the accuracy compared to traditional integrity tests. It will be a promising method for the future deep foundation assessment.
\end{abstract}

\section{INTRODUCTION}

As the world becomes more urbanized and the population increases progressively, challenges with land use and large-scale infrastructure suggest that deep foundations (i.e. piles) will become more common - larger and deeper. The associated pile repair and maintenance account for a significant part of the construction cost, which has put more focus on reliable structural health monitoring technologies and data interpretation in recent years.

As for deep foundation, the intrinsic nature of underground structures adds considerable difficulties to monitoring their response under various loading and environment conditions [1,2]. Anomalies present in piles, for example voids, soil intrusions, material

Q. Sun, Laing O'Rourke Centre for Construction Engineering and Technology, Department of Engineer-ing, University of Cambridge, Cambridge, U.K., Email: qs217@cam.ac.uk

M.Z.E.B. Elshafie*, Corresponding Author, Department of Civil and Architectural Engineering, Qatar University, Doha, Qatar., Email: melshafie@qu.edu.qa 
loss or shaft collapse, could result in structure instability and/or durability issues. Without adequate monitoring techniques and appropriate identification and data interpretation methods, these anomalies could go undetected. However, the current technologies still cannot provide an accurate and reliable anomaly detection system [3,4]. As such, an in-depth study of concrete hydration and heat development is urgently needed.

In this paper, a new thermal integrity testing method is proposed. Distributed temperature sensors are deployed on the steel cage to monitor the early-age concrete temperature development and to study pile integrity. Aided with numerical simulation, it is hypothesized that a reliable cast in-situ concrete structure interpretation tool for real time anomaly detection and structural health diagnosis can be developed. Details of the new integrity testing method are discussed in this paper. The concrete hydration model and the numerical method are illustrated. Some modelling results of the new method are presented, followed by conclusions at the end of this paper.

\section{PILE THERMAL INTEGRITY TESTING METHOD}

\section{Proposed new method}

Cast in-situ piles are prone to have structural defects and imperfections that damage pile structural integrity and thus jeopardize geotechnical load capacity. Piles, geotechnical elements, that are buried underground, by nature cannot be visually inspected to ensure their quality. Therefore, multiple test methods are used worldwide to verify the loading capacity of piles and detect potential anomalies, among which non-destructive integrity testing is a common method for pile quality assurance $[3,5,6]$. Potential anomalies - such as voids, soil intrusions and cross-section variations - are expected to be captured through these integrity tests.

Three non-destructive integrity tests are widely used in industry, all of which, however, have significant limitations for pile monitoring. The maximum depth of the Pulse Echo test is limited by the presence of stiff soil or rock. The Crosshole Sonic Logging (CSL) method cannot provide information of concrete cover outside the steel cage. Gamma-gamma Logging (GGL) only assess very limited area around the access tubes. Therefore, a new reliable and accurate integrity method is necessary.

The proposed new method relies on measuring the amount of heat generated during concrete curing. For a cast in-situ concrete element, the heat generation and dissipation are a function of the concrete mix, element geometry, and boundary conditions. If defects such as voids, necking, bulging and/or soil intrusion exist inside the concrete body, they will result in local temperature variations. Commonly, a local reduction of temperature indicates concrete material loss and is interpreted as a reduced pile diameter. Inversely, a sudden increase of temperature suggests a bulge should occur.

The new approach requires a numerical model for refined thermal integrity analysis and employs distributed temperature sensors along the pile. Only field test temperature profile cannot provide enough information for accurate anomaly detection. The comparison between thermal integrity testing data and numerical modelling results can provide further insights to identify the nature and geometry of anomalies. Figure 1 visually illustrates this approach. Firstly, field test collects distributed temperature data, which are 


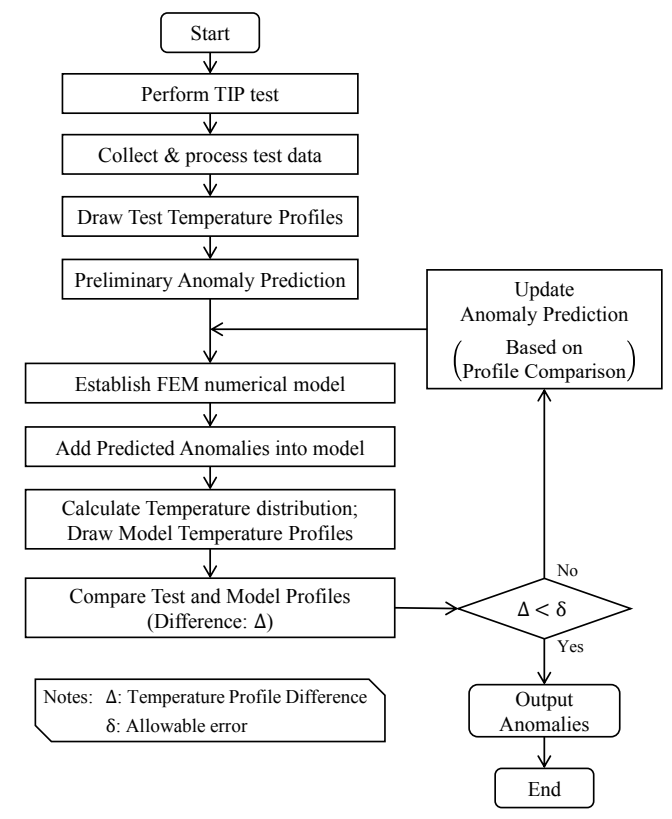

Figure 1: Thermal integrity testing anomaly detection system.

processed into temperature profiles versus time. Based on test results and temperature signatures, a preliminary prediction of anomalies is given. The numerical model is then established, and its results are compared to the field test temperature. If the difference exceeds allowable value (depends on geometry, generally $1{ }^{\circ} \mathrm{C}$ for small diameter piles), the anomaly types and distributions must be re-estimated. Then repeated the above procedures until the model results match the test profiles.

The key procedure of this approach is to build an accurate and reliable numerical model, with which pile anomaly detection capacity can be significantly improved. Cement hydration model is reviewed in the following section. The thermally activated and exothermic characteristics of the cement hydration as well as heat transfer mechanism need to be understood and modelled into the Finite Element Method (FEM) program.

\section{Concrete hydration model}

Hydration heat plays an important role in early-age concrete temperature development $[4,7,8]$. It is a complex chemical process highly depended on cement composition, reaction time and temperature. On the other hand, the rate and degree of hydration also significantly influences the mechanical properties of hardened concrete [9]. To quantify hydration production, many scholars have worked on an explicit formulas [10-18].

In this study, the hydration model by De-Schutter and Taerwe [10] is used for developing finite element temperature prediction program. The model has explicit and simpler mathematical expression. The hydration heat generation rate $Q$ is expressed as a function of the actual cement temperature $T(\mathrm{~K})$ and the degree of hydration $\alpha_{t}$ (the proportion of the amount of heat released at time $t$ to total heat of hydration).

$$
Q=q_{\max , 20} \cdot c \cdot\left[\sin \left(\alpha_{t} \pi\right)\right]^{a} \cdot \exp \left(b \alpha_{t}\right) \cdot \exp \left(\frac{E}{R}\left(\frac{1}{293}-\frac{1}{T}\right)\right)
$$

where $a, b$ and $c$ are hydration parameters dependent on material properties; $q_{\max , 20}$ 


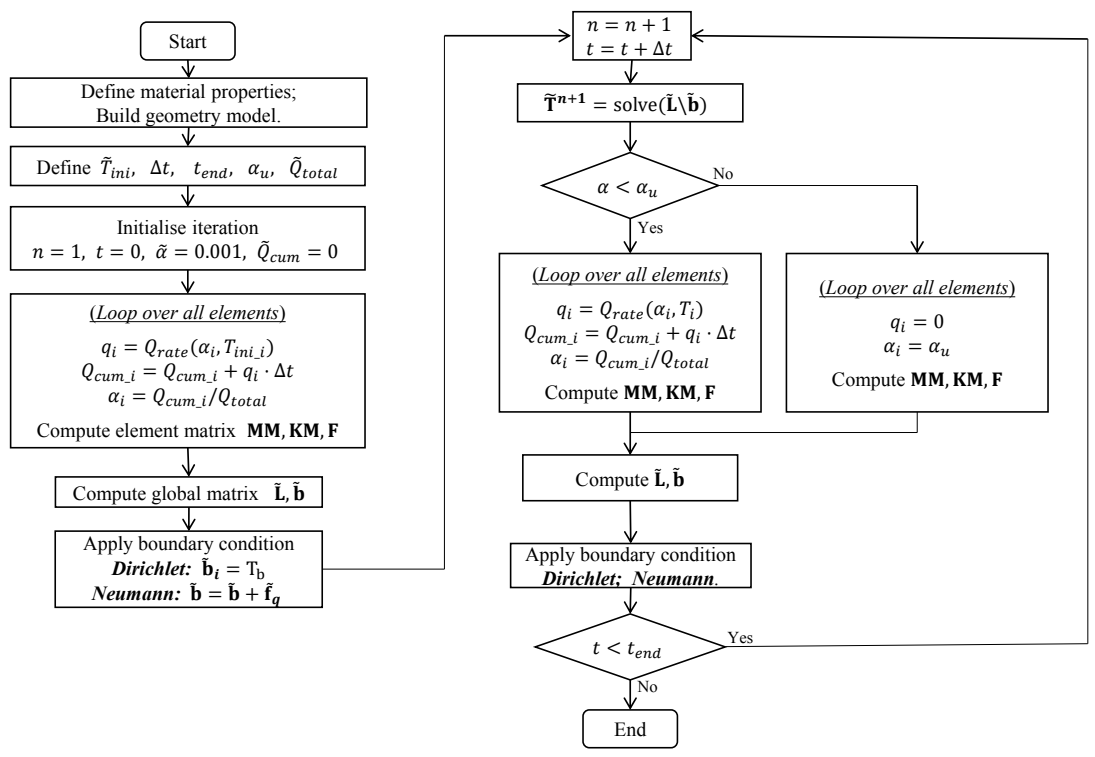

Figure 2: FEM programming flowchart.

is the maximum heat generate rate at $20{ }^{\circ} \mathrm{C} ; E$ is the apparent activation energy; and $R$ is the universal gas constant. The above heat of hydration formula applies to Type I cement. A modified version for Type III cement with blast furnace slag can be found in [10].

\section{NUMERICAL MODEL}

The key to this new method is to develop a numerical model for early-age concrete temperature development. The governing equation of concrete heat transfer can be expressed by the following heat diffusion equation based on the Fouriers Law:

$$
k \nabla \cdot(\nabla T)=\rho c \frac{\partial T}{\partial t}+Q
$$

where $k$ is the thermal conductivity, $\rho$ is the concrete density and $\mathrm{c}$ is the concrete heat capacity. The rate of internal heat generation $Q$ is defined as hydration heat.

Then, the numerical model using finite element method is established following standard interpolation strategy, $T=\mathbf{N T}$, where $\mathbf{N}$ denotes the interpolation shape function and $\mathbf{T}$ designates the nodal temperature for a given finite element mesh. The programming details of the FEM model is shown in Figure 2. The first step is to define all the material properties, including $k, \rho, c$ and others related to the hydration model. Then, the geometry with pre-defined mesh will be imported. Gmesh, Abaqus or Hypermesh are suitable for geometry building and mesh generation.

The weak form of the heat diffusion Eq. (2) in the domain $\Omega$ is expressed as the following equation:

$$
\int_{\Omega} \mathbf{N}^{\top} \frac{\partial}{\partial t} \mathbf{N T} d \Omega=\int_{\Omega} \mathbf{N}^{\top} \nabla^{\top}(\mathbf{K} \nabla \mathbf{N T}) d \Omega+\int_{\Omega} \mathbf{N H} \mathbf{N}^{\top} d \Omega
$$

where $\mathbf{H}$ is the nodal heat production rate matrix and $\mathbf{K}$ is the nodal thermal conductivity matrix. The nodal values of these two matrices equal to $Q / \rho c$ and $k / \rho c$. 
The equation is then discretised into many time steps. The simplified formula is obtained bellow:

$$
\left(\frac{\mathbf{M M}}{\triangle t}+\mathbf{K M}\right) \mathbf{T}^{n+1}=\frac{\mathbf{M M}}{\triangle t} \mathbf{T}^{n}+\mathbf{F}
$$

where $\mathbf{M M}, \mathbf{K M}$ and $\mathbf{F}$ are mass matrix, stiffness matrix and force matrix respectively, which represent the domain integration in Eq. (3). The above element matrix form is then expanded to the global matrix in the domain $\Omega$ as shown in Eq. (5).

$$
\widetilde{\mathbf{L}} \widetilde{\mathbf{T}}^{n+1}=\widetilde{\mathbf{R}} \widetilde{\mathbf{T}}^{n}+\widetilde{\mathbf{F}}=\widetilde{\mathbf{b}}
$$

While implementing the program, note that the initial degree of hydration should be set as a small value instead of zero, or else run time error will occur. Before each time loop, it is necessary to check whether the degree of hydration of each element is less than the ultimate degree of hydration. If not, the heat production rate shall return to zero. All the notations in the flowchart with tilde $\left(^{\sim}\right)$ are the global matrix, and bold notations mean element matrix. The nodal number is represented by subscript $i$. The system temperature $\widetilde{\mathbf{T}}$ is updated in each iteration.

\section{MODELLING RESULTS}

\section{Hydration model setups}

Following FEM modelling technique in the previous section, a hypothetical case study using this method is presented in this section. The two-dimensional FEM modelling results are demonstrated. The heat hydration model by [10] is used to simulate temperature development of early age concrete during curing. The heat production rate is expressed in Eq. (1).

Five basic properties of theconcrete and ambient environment are listed in Table I. In this hypothetical case, cement is the only source of hydration heat in the concrete. It takes up about $13 \%$ of concrete by weight in this hypothetical case study. Thus, the maximum heat production rate and total released heat for concrete equal $13 \%$ of pure cement $q_{\max .20}($ cement). To set the parameter in line with FEM programming, cement heat generation by weight is then converted to heat generation by volume $q_{\max .20}$ (concrete), which is $13 \% \times q_{\max .20}($ cement $) \times \rho$. Hence, the values of all hydration model parameters are obtained and listed in Table II.

The hypothetical case is a cylinder pile with a diameter of $400 \mathrm{~mm}$. The height is 2 meters. The concrete is cast in a semi-adiabatic environment, and circumferential bound-

TABLE I: PARAMETERS OF MATERIAL PROPERTIES

\begin{tabular}{llllll}
\hline Parameters & $\rho\left(\mathrm{kg} / \mathrm{m}^{3}\right)$ & $c(\mathrm{~J} / \mathrm{kg} . \mathrm{K})$ & $k(\mathrm{~W} / \mathrm{m} . \mathrm{K})$ & $h_{c}(\mathrm{~W} / \mathrm{m} . \mathrm{K})$ & $T_{\text {env }}(\mathrm{K})$ \\
\hline Values & 2200 & 1000 & 1.0 & 1.2 & 288 \\
\hline
\end{tabular}

TABLE II: PARAMETERS OF HYDRATION MODEL

\begin{tabular}{cccccccc}
\hline Parameters & $a$ & $b$ & $c$ & $q_{\max , 20}\left(\mathrm{~J} / \mathrm{m}^{3} \mathrm{~s}\right)$ & $Q_{\text {total }}\left(\mathrm{J} / \mathrm{m}^{3}\right)$ & $E(\mathrm{~J} / \mathrm{mol})$ & $R(\mathrm{~J} / \mathrm{mol} . \mathrm{K})$ \\
\hline Values & 0.667 & 3.0 & 2.6 & 617 & $77.22 \times 10^{6}$ & 33500 & 8.31 \\
\hline
\end{tabular}




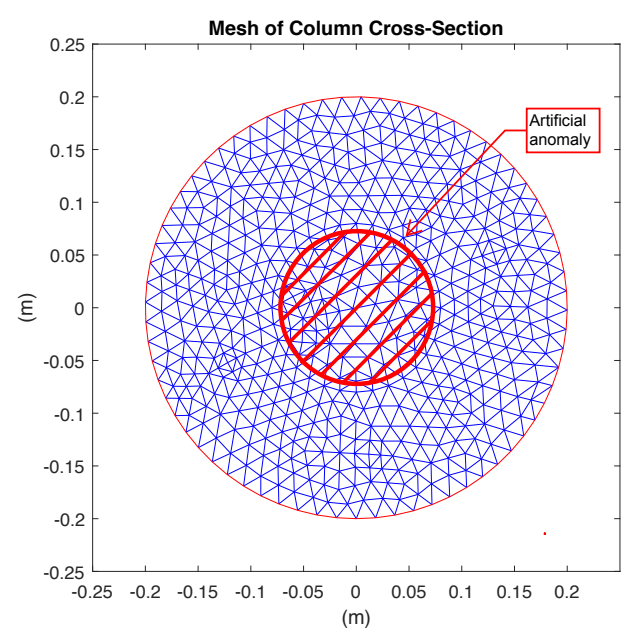

(a) Geometry mesh

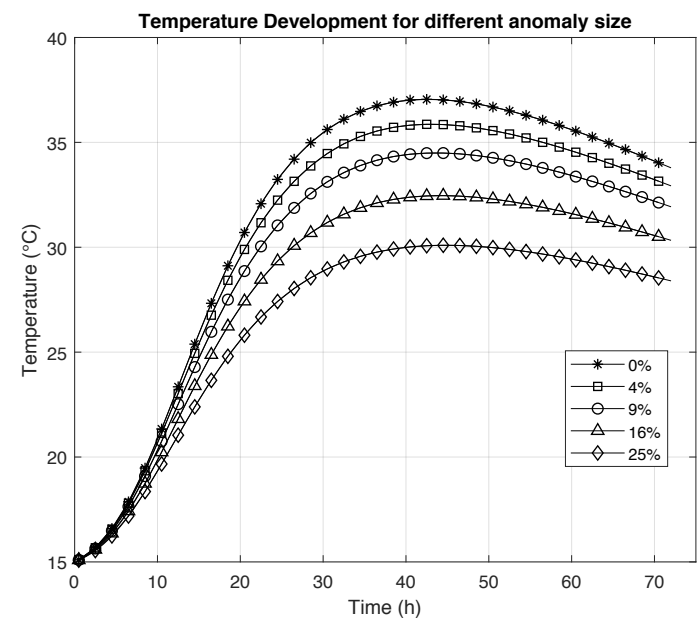

(b) Temperature development

Figure 3: Two-dimensional FEM Model

ary heat flux coefficient $h_{c}$ is $0.5 \mathrm{~W} / \mathrm{m} . \mathrm{K}$. Distributed temperature sensor is attached on the steel case which is $25 \mathrm{~mm}$ from concrete cover.

\section{Two-dimensional modelling}

In this two-dimensional model, artificial anomalies with various sizes will be built. Figure 3 a shows the geometry mesh discretised by 3 -node triangular elements. The hollow section in the middle represents the anomaly with poor concrete quality and/or air bubble. As the pile is relative long $(2 \mathrm{~m})$ compared to the diameter $(0.4 \mathrm{~m})$, it is reasonably accurate to employ $2 \mathrm{D}$ hypothesis for concrete heat hydration simulation.

This hypothetical case focuses on investigating the influence of anomaly size on the temperature variation. Anomalies of different sizes are built in the geometry, namely $4 \%$, $9 \%, 16 \%$ and $25 \%$ of the cross-section area. One control geometry without any anomaly is also simulated. The distributed temperature sensor is attached to the steel cage, which is located at $25 \mathrm{~mm}$ from concrete cover. Figure $3 \mathrm{~b}$ shows the temperature development due to hydration heat transfer at the sensor location. The line with the star markers indicates the control pile temperature development. As the size of anomaly increases, the temperature drops more evidently. The temperature variation due to anomalies is up to $7{ }^{\circ} \mathrm{C}$ at 40 hours.

\section{Two-dimensional axisymmetric modelling}

The axial symmetry of concrete pile allows the use of one-dimensional axisymmetric model. The model is expanded to two-dimensional axisymmetric model to simulate 3D effect. The geometry mesh discretised by 3-node triangular elements is shown in Figure $4 \mathrm{a}$. The height of the pile is $2 \mathrm{~m}$. The central anomaly height is $400 \mathrm{~mm}$, with a radius of $80 \mathrm{~mm}$. Heat flux on the top and bottom boundary is $0.5 \mathrm{~W} / \mathrm{m} . \mathrm{K}$.

In this model, the distributed temperature is parallel to the pile boundary at $25 \mathrm{~mm}$. Figure $4 \mathrm{~b}$ demonstrates the temperature profile due to early-age concrete hydration at different time. The initial temperature is $15^{\circ} \mathrm{C}$, and it gradually raise to the maximum 


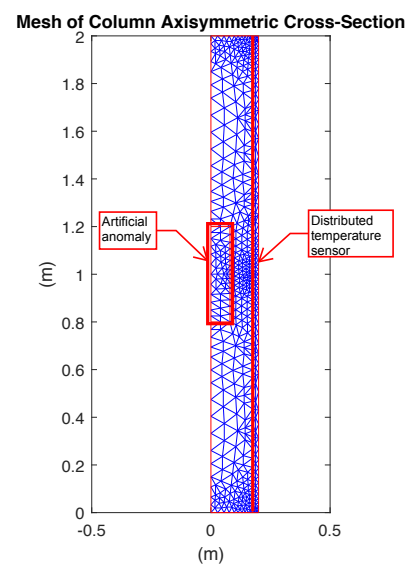

(a) Geometry mesh

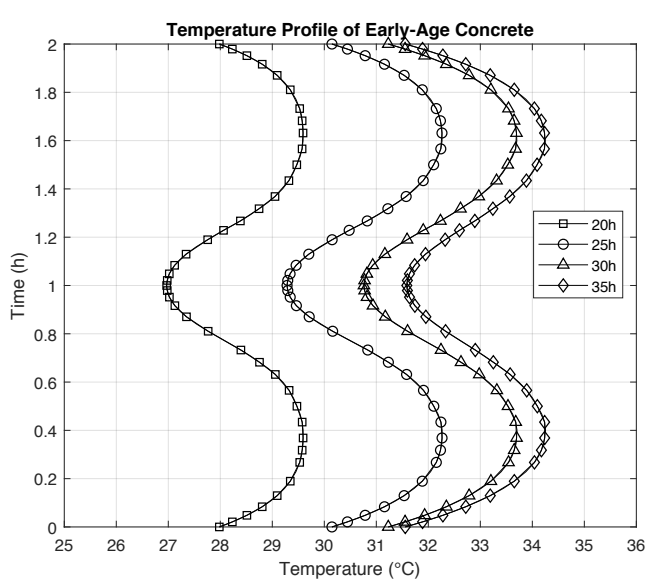

(b) Temperature development

Figure 4: Two-dimensional axisymmetric FEM Model

temperature around 40 hours. At the $1 \mathrm{~m}$ height, temperature drops evidently in the temperature profile. As central anomaly does not release heat, a decrease of $2.5{ }^{\circ} \mathrm{C}$ on the temperature profile (Figure $4 \mathrm{~b}$ ) indicates a potential defect at that location.

\section{CONCLUDING}

A new anomaly-detection system for cast in-situ concrete structures is presented in this paper. The new method compensates the limitations of traditional integrity testing technologies. It makes accurate and reliable anomaly detection possible. The new method also has the potential to identify pile defect size, nature and precise location.

The method employs Finite Element Method to model early-age concrete hydration and heat transfer within the concrete body. The concrete hydration model developed by De Schutter is able to accurately simulate heat production rate during the whole curing process and compatible for both Type I and Type III cement. The temperature development of the concrete body is predicted by FEM program, which has demonstrated its capacity to capture anomalous temperature profile and thus detect anomalies.

The new thermal integrity testing method shows good promise and hence good potential to localise and identify anomalies for pile foundation. It is anticipated that this method, with continuous research and further refinement, will greatly facilitate deep foundation assessment with a lower cost and higher accuracy.

\section{ACKNOWLEDGEMENT}

This work was performed in the framework of ITN-FINESSE, funded by the European Unions Horizon 2020 research and innovation program under the Marie SkodowskaCurie Action grant agreement n 722509. The corresponding author Dr. Mohammed Elshafie would like to acknowledge the support of Qatar University for attending this conference. 


\section{REFERENCES}

1. Matsumoto, T., P. Kitiyodom, H. Matsui, and Y. Katsuzaki. 2004. "Monitoring of load distribution of the piles of a bridge during and after construction," Soils and foundations, 44(4):109-117.

2. Kister, G., D. Winter, Y. M. Gebremichael, J. Leighton, R. A. Badcock, P. D. Tester, S. Krishnamurthy, W. Boyle, K. Grattan, and G. F. Fernando. 2007. "Methodology and integrity monitoring of foundation concrete piles using Bragg grating optical fibre sensors," Engineering Structures, 29(9):2048-2055.

3. Zhang, H. L. and C. T. Davie. 2013. "A numerical investigation of the influence of pore pressures and thermally induced stresses for spalling of concrete exposed to elevated temperatures," Fire Safety Journal, 59:102-110.

4. Rui, Y., C. Kechavarzi, F. O’Leary, C. Barker, D. Nicholson, and K. Soga. 2017. "Integrity testing of pile cover using distributed fibre optic sensing," Sensors, 17(12):2949.

5. Phan, L. T., J. R. Lawson, and F. L. Davis. 2001. "Effects of elevated temperature exposure on heating characteristics, spalling, and residual properties of high performance concrete," Materials and structures, 34(2):83-91.

6. Zou, X., A. Chao, Y. Tian, N. Wu, H. Zhang, T. Yu, and X. Wang. 2012. "An experimental study on the concrete hydration process using Fabry-Perot fiber optic temperature sensors," Measurement, 45(5):1077-1082.

7. Ruiz, J. M., A. K. Schindler, R. O. Rasmussen, P. K. Nelson, and G. K. Chang. 2001. "Concrete temperature modeling and strength prediction using maturity concepts in the FHWA HIPERPAV software," in Seventh International Conference on Concrete Pavements. The Use of Concrete in Developing Long-Lasting Pavement Solutions for the 21 st CenturyInternational Society for Concrete Pavements, vol. 1.

8. Rui, Y. and M. Yin. 2017. "Thermo-hydro-mechanical coupling analysis of a thermo-active diaphragm wall," Canadian Geotechnical Journal, 55(5):720-735.

9. Neville, A. M. 1995. Properties of concrete, Pearson Education India.

10. De-Schutter, G. and L. Taerwe. 1995. "General hydration model for Portland cement and blast furnace slag cement," Cement and Concrete Research, 25(3):593-604.

11. De-Schutter, G. and L. Taerwe. 1996. "Degree of hydration-based description of mechanical properties of early age concrete," Materials and structures, 29(6):335.

12. Schindler, S. K. 2004. "Effect of temperature on hydration of cementitious materials," $M a$ terials Journal, 101(1):72-81.

13. Schindler, A. K. and K. J. Folliard. 2005. "Heat of hydration models for cementitious materials," ACI Materials Journal, 102(1):24.

14. Riding, K. A., J. L. Poole, K. J. Folliard, M. C. Juenger, and A. K. Schindler. 2011. "New Model for Estimating Apparent Activation Energy of Cementitious Systems." ACI Materials Journal, 108(5).

15. Tomosawa, F. 1997a. "Development of a kinetic model for hydration of cement," Proc. of the 10th Int. Cong. on the Chem. of Cem., Gothenburg, Sweden.

16. Tomosawa, F., T. Noguchi, and C. Hyeon. 1997b. "Simulation model for temperature rise and evolution of thermal stress in concrete based on kinetic hydration model of cement," in Proceedings of tenth international congress chemistry of cement, vol. 4, pp. 72-75.

17. Park, K. B., T. Noguchi, and J. Plawsky. 2005. "Modeling of hydration reactions using neural networks to predict the average properties of cement paste," Cement and Concrete Research, 35(9):1676-1684.

18. Wang, X. Y. and H. S. Lee. 2010. "Modeling the hydration of concrete incorporating fly ash or slag," Cement and concrete Research, 40(7):984-996. 